\title{
Tamarind Seed Extract Enhances Epidermal Wound Healing
}

\author{
Mohd Yusof bin Mohamad, Haris B Akram \& Dinie Najwa Bero \\ Department of Biotechnology, Faculty of Science \\ International Islamic University Malaysia, Jalan Istana \\ Bandar Indera Mahkota, Kuantan, Pahang 25200, Malaysia \\ Mohammad Tariqur Rahman (Corresponding author) \\ Department of Biotechnology, Faculty of Science \\ International Islamic University Malaysia, Jalan Istana \\ Bandar Indera Mahkota, Kuantan 25200, Malaysia \\ Tel: 60-9571-6400 ext 2805 E-mail: tarique@iium.edu.my
}

Received: September 20, 2011

Accepted: October 9, $2011 \quad$ Published: January 1, 2012

doi:10.5539/ijb.v4n1p81

URL: http://dx.doi.org/10.5539/ijb.v4n1p81

\begin{abstract}
Traditional healing power of tamarind fruits and the established antioxidant activity of the seeds drive the present study. Wound healing efficiency of tamarind seed was evaluated. Different solvents: phosphate buffer saline (PBS), water, methanol and ethanol were used to prepare the extract. Circular wound was inflicted on the nape. $10 \mu \mathrm{lof} 5 \mu \mathrm{g} / \mathrm{ml}$ of extract was applied topically twice daily. Wound area was measured using Adobe ®Photoshop C3 Extended version and the percentage of wound reduction was calculated. PBS extract treatment induced complete wound healing in shortest period (10 days) while water extract, methanol extract and Solcoseryl ointment treatment induced complete wound healing in 11 days and control groups without any treatment took 14 days to heal. Phytochemical screening and Bradford method for protein quantification reveals the presence of alkaloid, saponin and tannin in all samples except PBS extract which tested negative to tannin. Flavonoid tested positive in methanol and ethanol extracts.
\end{abstract}

Keywords: Wound healing, Tamarind seed extract, Solcoseryl, Phytochemicals

\section{Introduction}

Plant materials have been used traditionally as medicine for treating ailments and maintaining health Tamarindus indica $\mathrm{L}$. is one of the reported ancient herbal medicine plants (Soemardji, 2007). The healing power of tamarind is first mentioned in the traditional Sanskrit literatures. In Europe, the medical properties of tamarind were well known after it has been introduced by the Arab traders. Tamarindus indica L. fruit is useful as an agent of antihelmintic, antidiarrheal and anti-emetic (Khan et al., 2005). Apart from the other components of the fruit, seeds of tamarind are commercially and nutritionally valuable.

Tamarind seed coat exhibit antioxidant activity when extracted with ethyl acetate and ethanol (Tsuda et al., 1994; Luengthanaphol et al., 2004).Tamarind seeds inhibit activities of snake envenomation enzymes which are responsible for local tissue damage, inflammation and hypotension (Ushanandini et al., 2006). Polysaccharide isolated from tamarind seeds has biological applications. It has immunomodulatory effect and lacks carcinogenic and cytotoxic activities (Sreelekha et al., 1993; Sano et al., 1996; Ieda et al., 1978). Water extract of tamarind seed was found to reduce blood sugar level in Streptozotocin-induced diabetic male rats (Maiti et al., 2004). In addition, tamarind seeds known to have high inhibitory activity against human neutrophil elastase (Fook et al., 2005). Human neutrophil elastase is release by neutrophil during inflammation but excessive production will lead to emphysema. Tamarind seed polysaccharide (TSP) has been shown to improve dry eye syndrome, to assist release of drug in human body and intraocular penetration of Rufloxacin (Rolando \& Valente, 2007; Sumathi \& Ray, 2002; Ghelardi et al., 2004). Wound healing is one of the major concerns among health care practitioners and scientists. Poor wound healing not only cause trauma to the patient but increase the burden of financial resources and requirement for cost effective management within health care system (Bowler et al., 2001). 
In the present study, influence of tamarind seeds on wound healing was demonstrated. Different types of tamarind seed extracts, Phosphate Buffer Saline (PBS), water, methanol and ethanol extract have been used as the treatment groups in this study. The aim of this study is to evaluate the effect of these extracts on wound healing. The findings of this study may become a starting point for a better formulation of treatment for wound healing.

\section{Methods}

\subsection{Collection of Tamarind seeds}

Raw tamarind seeds were collected from Perusahaan Sinarmaju located in Kempas, Johor, Malaysia. The size of the tamarind seeds were approximately $3 \times 2 \times 2 \mathrm{~cm}^{3}$.

\subsection{Preparation of the extracts}

Four types of extracts were prepared namely PBS, water, methanol and ethanol. The air dried seeds were grounded using mechanical grinder several times until it became homogenous powder. PBS and water extract were prepared by mixing each $100 \mathrm{~g}$ of grounded powder with $400 \mathrm{ml}$ of solvents (sterile distilled water, methanol, ethanol or PBS) according to 1:4 w/v ratios in volumetric flask. The mixture was placed in incubator-shaker for 8 hours at $37^{\circ} \mathrm{C}$. The supernatant from the flask was centrifuged at $200 \mathrm{~g}$ at $27^{\circ} \mathrm{C}$ for 30 minutes. The supernatant was then freeze-dried to obtain the final extraction in powder form. Methanol and ethanol extraction were prepared using Soxhlet apparatus for 10 hours and the supernatant was then freeze-dried to obtain the final extract in powder. Weights of the final form of the extract were recorded to determine the yield.

\subsection{Inducing wounds in test animals (mice) and application of the extract}

Female ICR mice were used as the test sample to observe the wound healing rate. The mice were purchased from Institute of Medical Research, Kuala Lumpur, Malaysia and housed under standard experimental conditions of temperature $25 \pm 2^{\circ} \mathrm{C}$ with a 12 hour light/dark cycle and fed on normal pellet diet and tap water ad libitum. The mice were 7-8 weeks old and 25-30 $\mathrm{g}$ at the time when wound was induced. A uniform circular epidermal wound was made at the dorsal part of the mice using a $6 \mathrm{~mm}$ biopsy punch. Prior to excision, the mice were anesthetized using intraperitoneal administration of $6 \%$ Nembutal [Ceva Sante Animale ${ }^{\mathrm{TM}}$ ] $0.1 \mathrm{~mL} / 10 \mathrm{~g}$ of body weight. The fur was shaved off and the skin was swabbed with alcohol pads and let dry. The extract $(\sim 10 \mu \mathrm{L})$ was applied twice a day, once in the morning,

\subsection{Observation of wound healing rate}

Pictures of the wounds from the first day of the wound induction until the day of complete wound closure (CWC), i.e., complete healing were taken on each alternative day to measure the rate of wound healing and comparative wound healing efficiency of the extracts. A Canon Powershot 5.0MP digital camera (Canon, NY, USA) was used for taken the wound pictures. Pictures were taken with insistent features such as distance, aperture. A $15 \mathrm{~cm}$ ruler was used as a scale to measure the size of the wound. The pictures were analyzed for wound surface area using Adobe ${ }^{\circledR}$ CS3 Photoshop (Extended Version), and the data analyzed using SPSS for Windows version 16.0 software.

Percent relative healing efficiency (RHE) of the extracts was calculated to measure how fast the extracts can completely heal the wound when compared with the time required for complete healing without any medicine or extract (natural healing). Percent RHE was calculated using the following formula:

$$
\begin{aligned}
& \% \text { relative wound } \\
& \text { healing efficiency }
\end{aligned}=\frac{T_{N}-T_{E}}{T_{N}} \times 100
$$

$\mathrm{T}_{\mathrm{N}}=$ Time required for natural wound healing i.e., $\mathrm{CWC}$ without any drug/extract. $\mathrm{T}_{\mathrm{E}}=$ Time taken for wound healing i.e., CWC with drug/extract. In the current study solcoseryl and series of extracts were used as shown in Table 2 .

\subsection{Phytochemical analysis of the extract}

A collection of tests was used for qualitative analysis of the phytochemicals present in the extract. The test used in this experiment was to determine the presence or absence of alkaloids, terpenoids, steroids, flavanoids, saponins and phenols. Bradford method was also used to quantify the protein content of the extracts.

2.5.1 Protein analysis using the Bradford assay (Bradford, 1976)

Briefly, the extracts were mixed together in a clear plastic $1 \mathrm{~mL}$ microcuvette with sodium chloride $(\mathrm{NaCl})$ and Bradford reagent ( $20 \mu \mathrm{L}$ of extract and $80 \mu \mathrm{L}$ of $\mathrm{NaCl}$ with $1000 \mu \mathrm{L}$ Bradford reagent) and the absorbance was 
read at $595 \mathrm{~nm}$. The resulting reading was compared to the standard solution of bovine serum albumin (Amresco ${ }^{\mathrm{TM}}$ ).

\subsubsection{Test for alkaloid (Dragendorff's Test)}

Two $\mathrm{ml}$ of the extract was mixed with a few drops of concentrated hydrochloric acid and a few drops of Dragendorff's reagent in a glass test tube. Yellow precipitate indicated the presence of alkaloids (Mojab et. al., 2003).

\subsubsection{Test for Terpenoid and Steroid (Libermann-Burchard Test)}

Two $\mathrm{ml}$ of the extract was mixed with 3-5 drops of acetic anhydride in a test tube and stirred to allow mixing. Then, 1-2 drops of concentrated sulphuric acid were added to the mixture by slowly dripping them down the test tube wall. Blue and purple coloration indicated the presence of terpenoids and steroids, respectively (Mojab et. al., 2003).

\subsubsection{Cyanidin Testing}

A piece of magnesium ribbon was dropped into a test tube containing $2 \mathrm{ml}$ of extract, followed by a few drops of concentrated hydrochloric acid. The solution is allowed to mix and settle for 10 minutes. Colour change and precipitate formation (if any) were observed. Yellow substance formation indicated presence of flavonoids (Mojab et. al., 2003).

\subsubsection{Tannin Testing}

Two $\mathrm{ml}$ of the extract was mixed with a few drops of iron (III) chloride solution in a test tube. Brownish green to blue black precipitate formation was indicative of tannins in the sample (Mojab et. al., 2003).

\section{Result}

\subsection{Total yield of the extracts}

Ethanol extract of tamarind seeds produced the highest yield with $66.2 \mathrm{~g}$ freeze-dried powder in $840 \mathrm{~g}$ of seeds (7.88\%). This is followed by methanol extraction with $119.5 \mathrm{~g}$ freeze-dried powder in $1.7 \mathrm{~kg}$ of seeds $(7.03 \%)$, PBS extraction with $4.62 \mathrm{~g}$ freeze-dried powder in $840 \mathrm{~g}$ seeds $(0.55 \%)$ and water extraction with $3.05 \mathrm{~g}$ freeze-dried powder in $1.14 \mathrm{~kg}$ of seeds $(0.27 \%)$.

\subsection{Presence and absence of phytochemicals}

The presence of alkaloid, flavanoid, saponin, terpenoid, steroid and phenol in different extract were analyzed. Terpenoid and steroid were absent in all samples. Alkaloid and saponin were tested positive in all samples. Only methanol and ethanol extract gave positive result on flavonoid testing. Tannin was detected in all samples except PBS extract (Table1). Total protein content of the extract can only be determined for PBS extract. Average protein content in PBS extract was $40 \mu \mathrm{g} / 100 \mu \mathrm{g}$ of extract.

\subsection{Tamarind seeds extract (TSE) significantly reduced wound healing time}

TSE were found to require significantly shorter time for wound healing. Time (days) required for complete wound healing in different TSE are as follow: PE-10, WE-11, ME-11 and EE-12 (Table 2). PE showed the fastest healing time which was at day $10 \pm 0.00$. It was followed by positive control at day $11 \pm 0.37$, WE at day $11 \pm 0.40, \mathrm{ME}$ at day $11 \pm 0.40, \mathrm{EE}$ at day $12 \pm 0.00$ and negative control at day $14 \pm 0.68$ (Table 2). The rate of wound healing (\% reduction of wound area per day) varies according to the types of extract. For 50\% reduction of the initial wound area, approximately $3,3.5,3.5$, and 4.5 days were required for PE, WE, ME and EE respectively. For $75 \%$ wound reduction, nearly 5.8, 6, 6 and 6.5 days were required for WE, PE, ME and PE respectively (figure 1).

\subsection{Ethanol extract exhibited faster wound closure in the early phase}

About $47 \%$ of the initial wound area was reduced in the first two days when EE was applied. At day 4, all treatment except ME showed noticeable wound reduction, PE was the highest with $58.32 \%$ followed by WE (54.19\%) and EE (51.27\%). At day 6, all treatments were significant and demonstrated high percentage of wound reduction, WE was the highest with 80.56\%, PE (77.28\%), ME (75.72\%) and EE (71.20\%) figure 1.

\subsection{PBS extract exhibits the fastest wound closure rate at later phase}

PE demonstrated better wound reduction compared to all treatment group while EE showed the lowest. At day 8 , WE continue to become the highest in wound reduction with $94.49 \%$, PE $(93.28 \%)$, ME $(91.76 \%)$ and EE $(89.33 \%)$. Complete wound healing was observed at day 10 only with PE. At day 10, ME (98.63\%) and WE $(98.61 \%)$ have almost similar rate of reduction and this rate is significantly higher than control group. However, 
percent reduction of wound size with EE (94.61\%) was not significant when compared with the control. Mostly on day 12, treatment with all TSE resulted in complete wound healing.

\section{Discussion}

About $80 \%$ of world population in Asia and Africa depend on traditional medicine for primary health care (WHO, 2008). Tamarind is considered as one of the useful traditional medicine used in South East Asia. Different parts of tamarind with different types of solvent have been used by researcher for investigating its medicinal properties. In present study, PBS, water, methanol and ethanol were used as the extraction solvent. PBS and water are chosen because of their isotonic and physiological features that are favorable for extracting protein and water soluble bioactive components (Anuar, et al., 2008). Non polar compounds that are present in tamarind seeds can be extracted by organic solvent. Thus, methanol and ethanol was used as the extraction solvent. The extraction was carried out at $37^{\circ} \mathrm{C}$ equal to normal physiological temperature and samples were incubated for 8 hours to preserve and maximize the protein yield. More than 8 hour incubation is not recommended for possible degradation by microbial contamination. The freeze-dried product was kept at $-80{ }^{\circ} \mathrm{C}$ to minimize protein loss due to enzyme degradation. Extracts were applied by mixing in deionized water to provide moisture in the wound bed which is essential for the enzymatic activity (Anuar, et al., 2008). Only female mice were chosen for this study because they are less aggressive compare to male mice. The excision was done at dorsal region of the mice to reduce the possible scratching of the wound. Female mice of known age and body weight range were used to maintain the constant physiological activity. Specific concentration of anesthetic agent (Nembutal) base on the animals' body weight was used to allow constant time of unconsciousness. The extract was applied few minutes after wounding and not immediately to avoid flush out by the wound. Wound healing is classified into inflammatory phase, proliferative phase, and maturational phase. Extract of tamarind seeds used in this study have been shown to have better wound healing. This result was expected due to several consistent findings on immunomodulatory, anti-toxicity, anti-venom, and antioxidant activity of tamarind seeds (Sreelekha et al., 1993; Sano et al., 1996; Ieda et al., 1978).

Tamarind seed flavonoids may be involved in stabilizing highly reactive, potential harmful free radicals and protect cells from oxidative damage. The ability of antioxidants to destroy highly reactive free radicals serves to protect the structural integrity of immune cells and prevents the loss of essential functions. This study proposes that tamarind seed flavonoids might contain bioactive components which act as antioxidant responsible for neutralizing the effect of free radicals which are normally generated by Oxygen-dependent mechanisms for intracellular killing by leukocytes as reported earlier (Sudjaroen et al., 2005). PE exhibits the fastest rate of healing that contains highest protein content. The fastest rate of healing could be attributed to Trypsin inhibitor, an important protein molecule involved in proliferation of fibroblast and collagen synthesis during wound healing (El-Siddig et al., 2006).

Phytochemical result showed that alkaloid and saponin were present in PE and additional tannin was present in WE. Alkaloid is known to assist in epithelization of wound and chemotaxis in fibrosis (Azeez et al., 2007). Saponin on the other hand stimulates angiogenesis by modifying the balance of protease/protease inhibitor secretion in human endothelial vascular cells (Morisaki, 1995). Tannin is believed to have haemostatic activity, arresting bleeding from damaged or injured vessels by precipitating proteins to form vascular plugs (Okoli, 2007). Possible combination of these chemicals may explain the fluctuation of wound reduction of PE and WE on day 4 to 8. Infections by a number of microorganisms such as P. aeruginosa, S. aureus, S. faecalis, E.coli, Clostridium perfringens, Clostridium tetani, Coliform bacilli and enterococcus are reported to be responsible for delayed wound healing (Bowler et al, 2001). The presence of tannin in WE therefore could be associated with faster wound closure due to its antimicrobial property.

Total protein content of PE was measured using Bradford method. The result indicated high presence of protein in the sample, $40 \%$ of the composition of the seeds. The finding is different when compared to the available literature. Different methods of extraction especially the incubation time in extraction may explain the difference in the amount of protein. In contrast, protein could not be detected in WE, ME and EE. The most likely reason for this is the occurrence of polyphenols in the samples. Bradford method is an easy and rapid protein quantitative method. The assay relies on the binding of the dye Commasie blue G250 to protein. The dye binds readily to arginiyl and lysyl residues of proteins but does not bind to free amino acids. This specificity leads to variation in response to different proteins. In addition, sodium ascorbate, phenol compounds, and metal ions existed in the samples may cause interference.

In conclusion, the present study has succeeded to achieve the objective of the research. The different effect of the tamarind extract on wound healing was observed. All extracts exhibited significant increase in the rate of healing. 
PBS extract was the most effective in increasing the rate of healing. Ethanol extraction on the other hand was the most effective in yielding tamarind seeds product. Phytochemical screening of the extracts reveals the presence of secondary metabolite such as alkaloid, flavonoid, saponin and tannin. PBS extract only contains protein in a very significant amount.

\section{Acknowledgements}

This work was supported by kulliyyah of science, IIUM. The authors are thankful to Nafiu .B. AbdurRazaq for his technical support.

\section{References}

Anuar, N. S., Zahari, S. S, Taib, I. A. \& Rahman, M. T. (2008). Effects of green and ripe Carica Papaya epicarp extracts on wound healing and during pregnancy. Food and Chemical Toxicology, 46 (7), 2384-2389. http://dx.doi.org/10.1016/j.fct.2008.03.025

Azeez, S., Amudhan, S. Adiga, S., Rao, N. \& Udupa., L. A. (2007). Wound healing profile of Area Catechu extract on differetnt wound models in wistar rats. Kuwait Medical Journal, 39 (1), 48-52

Bowler, P. G, Duerden, B. I. \& Amstrong, D. G. (2001). Wound microbiology and associated approaches to wound management.Clinical Microbiology Review.

Daniyan, S. Y. \& Muhammad, H. B. (2008). Evaluation of the antimicrobial activities and phytochemical properties of extracts of Tamaridus indica against some diseases causing bacteria, African Journal of Biotechnology Vol. 7 (14), pp. 2451-2453.

Doughari, J. H. (2006). Antimicrobial Activity of Tamarindus indica Linn. Tropical Journal of Pharmaceutical Research, 5 (2), 597-603.

El-Siddig, K., Gunasena, H. P. M., Prasad, B. A., et al. (2006). Tamarind, Tamarindus indica. Southampton Centre for Underutilised Crops, Southampton, UK.

Eming, S. A., Werner, S., Bugnon, P., et al. (2007). Accelerated wound closure in mice deficient for Interleukin-10. American Society for Investigative Pathology.

Fook, J. M. S. S. L., Macedo, L. L. P., Moura, G. E. D. D., et al. (2005). A serine proteinase inhibitor isolated from Tamarindus indica seeds and its effects on the release of human neutrophil elastase. J. Life Sciences, (76), 2881-2891. http://dx.doi.org/10.1016/j.lfs.2004.10.053

Ghelardi, E., Tavanti, A., Davini, P., et al. (2004). A mucoadhesive polymer extracted from tamarind seed improves the intraocular penetration and efficacy of Rufloxacin in topical treatment of experimental Bacterial Keratitis, Journal of Antimicrobial Agents and Chemotherapy, 48, 3396-3401. http://dx.doi.org/10.1128/AAC.48.9.3396-3401.2004

Goyal P., Kumar, V. \& Sharma, P. (2007). Carboxymethylation of Tamarind kernel powder, Carbohydrate Polymers, 69, 251-255. http://dx.doi.org/10.1016/j.carbpol.2006.10.001

Gunasena, H. P. M. \& Hughes, A. (2000). Tamarind.International Centre for Underutilized Crops, Southampton.

Haroon, Z. A., Amin, K., Jiang, X. \& Arcasoy, M. O. (2003). A novel role for erythropoietin during fibrin-induced wound-healing response, American Journal of Pathology, Vol. 163, No. 3 http://dx.doi.org/10.1016/S0002-9440(10)63459-1

Hunt, T. K., Hopf, H. \& and Hussain, Z. (2000). Physiology of Wound Healing, Adv Skin Wound Care. 13(2 Suppl), 6-11.

Iida, M., Matsunaga, Y., Matsuoka, N., Abe, M., Ohnishi, K. \& Tatsumi, H. (1978). Two years feeding toxicity study of tamarind seed polysaccharide in rats. J. Toxicol. Sci, 3(2), 163-192. http://dx.doi.org/10.2131/jts.3.163

Ishola, M. M., E. B. Agbaji \& A. S. Agbaji. (1990). A Chemical Study of Tamarindus indica L.(Tsamiya) Fruits Grown in Nigeria, J. Sci. of Food and Agricul, 51(1), 141-143. http://dx.doi.org/10.1002/jsfa.2740510113. http://dx.doi.org/10.1002/jsfa.2740510113

Iwu, M. M. (1993). Handbook of African Medicinal Plants, pg 65, CRC Press. ISBN 084934266X

Khan,R. A.,Siddiqui, S. A., Azhar, I. \& Ahmed, S. P. (2005). Preliminary screening of methanol and butanol extracts of tamarindus indica for anti-emetic activity.Journal of Basic and Applied Sciences, Vol.1 No.2 
Komutarin, T., Azadi, S., Butterworth, L., Keil, D., Chitsomboon, B., Suttajit, M. \& Meade, B. J. (2004). Extract of the seed coat of Tamarindus indica inhibits nitric oxideproduction by murine macrophages in vitro and in vivo. Journal of Food and Chemical Toxicology, 42(4), 649-658. http://dx.doi.org/10.1016/j.fct.2003.12.001

Krithika V., Radhai Sri. S. (2007). Value Added Product from Tamarind. Science Tech Entrepreneur. Tamil Nadu, India.

Luengthanaphol, S., Mongkholkhajornsilp, D., Douglas, S., Douglas, P.L., Pengsopa, L. \& Pongamphai, S. (2004). Extraction of antioxidants from sweet Thai tamarind seed coat: Preliminary experiments. Journal of Food Engineering, 63(3): 247-252. http://dx.doi.org/10.1016/j.jfoodeng.2003.07.006

Maiti, R., D. Jane, U. K. Das \& D. Ghosh.(2004). Antidibetic effect of aqueous extract of seed of Tamarindus indica L. in Streptozotocin-induced diabetic Rats, J.Ethnopharmacol,, 92(1), 85-91. http://dx.doi.org/10.1016/j.jep.2004.02.002

Morad, M. M., El Magoli, S. B. \& Sedky, K. A. (1978). Physico-chemical properties of Egyptian tamarind seed oil. Fette Seifen Anstrichmittel, 80:357-359. http://dx.doi.org./ 10.1002/lipi.19780800906

Mori, R., Kondo, T., Nishie, T., Ohshima, T. \& Asano, M. (2004). Impairment of skin wound healing in -1,4-Galactosyltransferase-Deficient Mice with reduced leukocyte recruitment, American Journal of Pathology, Vol. 164, No. 4. http://dx.doi.org/10.1016/S0002-9440(10)63217-8

Morisaki, N., Watanabe, S., Tezuka, M., et al. (1995). Mechanism of angiogenic effects of saponin from ginseng Radix rubra in human umbilical vein endothelial cells, British journal of pharmacology, 115, 1188-1193

Moss, S. E., Klein, R. \& Klein E. K.(2000). Prevalence of and Risk Factors for Dry Eye Syndrome, Arch Ophthalmol, 118:1264-1268.

Mustapha, A., Yakasat, I. A. \& Aguye, I. A. (1996). Effect of Tamarindus Indica L. on the bioavailability of aspirin in healthy human volunteers. European Journal of Drug Metabolism and Pharmacokinetics, 21(3), 223-226. http://dx.doi.org/10.1007/BF03189717

Nellis, D. W. (1994). Seashore plants of South Florida and the Caribbean: a guide to identification and propagation of xeriscape plants, Pineapple Press Inc.

Okoli, C. O., Akah, P. A \& Okoli A. S. (2007). Potentials of leaves of Aspilia africana (Compositae) in wound care: an experimental evaluation.

Rao, Y. S, Mathew, K \& Potty S. N (1999). 'Tamarind Tamarindus indica L. Research - A Review', Ind. Jour. of Arecanut, Spices and Medicinal Plants, 1(4), 127-45.

Rimbau, V., Cerdan, C., Vila, R. \& Iglesias, J. (1996). Anti-inflammatory activity of some extracts from plants used in the traditional medicine of North-African countries. Phytotherapy Research, 13(2), 128-132. http://dx.doi.org/10.1002/(SICI)1099-1573(199903)13:2<128::AID-PTR399>3.0.CO;2-7

Rolando, M., C. Valente. (2007). Establishing the tolerability \& performace of Tamarind Seed Polysacharide (TSP) in treating Dry Eye Syndrome: Result of Clinical Study, BMC Opthalmology.

Sano, M., E. Miyata, S. Tamano, A. Hasiwara, N. Ito \& T. Shirai. (1996). Lack of Carcinogenicity of Tamarind Seed polysacharide in B6C3F1 Mice, Food Chem. Toxicol., 34(5), 463-467. http://dx.doi.org/10.1016/0278-6915(96)87356-X

Siddhuraju, P. (2005). The antioxidant activity and free radical-scavenging capacity of phenolics of raw and dry heated moth bean (Vigna aconitifolia) (Jacq.) marechal seed extracts, Food Chemistry, 99 (2006), 149-157.

Soemardji, A. A. (2007), Tamarindus Indica L. or "Asam Jawa": The sour but sweet and useful. [Online] Available: http://www.inm.utoyama.ac.jp/nennpo/07nennpo/07review_article.pdf (15March 2009)

Sone, Y. and Sato, K. (1994). Measurement of oligosaccharides derived from tamarind xyloglucan by competitive ELISA assay. Bioscience Biotechnology and Biochemistry, 58, 2295-2296. http://dx.doi.org/10.1271/bbb.58.2295

Sreelekha, T. T., T.Vijayakumar, R. Ankanthil, K. K. Vijayan \& M. K. Nair. (1993). Immunomodulatory effect of a polysaccharide from Tamarindus Indica, Anticancer Drugs, 4(2), 209-212. http://dx.doi.org/10.1097/00001813-199304000-00013

Sudjaroen, Y., Haubner, R. Wu, G., Hull, W. E. (2005). Isolation and structure elucidation of phenolic antioxidants from Tamarind (Tamarindus indica L.) seeds and pericarp. Food and Chemical Toxicology, 43, 1673-1682. 
Sumathi, S., Ray, A. R. (2002). Release behaviour of drugs from Tamarind seed polysaccharide tablets. $J$ Pharm Pharmaceut Sci, 5(1):, 12-18.

Traditional Medicine. (2008), World Health Organization. [Online] Available: http://www.who.int/mediacentre/factsheets/fs134/en/ (February15, 2009).

Tsuda, T., Osawa, T., Watanabe, M., Ohshima, K. \& Yamamoto, A. (1994). Antioxidative components isolated from the seeds of tamarind (Tamarindus indica L). Journal of Agriculture and Food Chemistry, 42(12), 2671-2674. http://dx.doi.org/10.1021/jf00048a004

Ushanandini, S., S. Nagaraju, K.H. Kumar, et al. V.Gowda, K.S.Girish. (2006). The Anti-snake venom Properties of Tamarindus indica (Leguminiceae) seed Extract, Phytotherapy research, 20(10), 851-858.

Yean Soon Y., Barlow P. J. (2004). Antioxidant activity and phenolic content of selected fruit seeds, Journal of Food Chemistry, 88, 411-417. http://dx.doi.org/10.1016/j.foodchem.2004.02.003

Table 1. Qualitative phytochemical analysis of tamarind seed extract

\begin{tabular}{|c|c|c|c|c|}
\hline Samples & PE & WE & ME & EE \\
\hline Alkaloid & $\checkmark$ & $\checkmark$ & $\checkmark$ & $\checkmark$ \\
\hline Terpenoid & $\times$ & $\times$ & $\times$ & $\times$ \\
\hline Steroid & $\times$ & $\times$ & $\checkmark$ & $\checkmark$ \\
\hline Flavonoid & $\times$ & $\checkmark$ & $\checkmark$ & $\checkmark$ \\
\hline Saponin & $\checkmark$ & $\checkmark$ & $\times$ Absent \\
\hline Tannin & $\times$ & & \\
\hline
\end{tabular}

Table 2. Number ( mean) of days required for complete healing of induced wounds

\begin{tabular}{|c|c|c|}
\hline $\begin{array}{c}\text { Treatment group } \\
(\mathrm{n}=7)\end{array}$ & $\begin{array}{c}\text { Days required for complete healing } \\
(\text { mean } \pm \text { S.E.M })\end{array}$ & \% RHE \\
\hline NC & $14 \pm 0.68$ & 0.21 \\
\hline PC & $11 \pm 0.37$ & 0.29 \\
\hline PE & $10 \pm 0.00^{\mathrm{a}}$ & 0.21 \\
\hline WE & $11 \pm 0.40^{\mathrm{a}}$ & 0.21 \\
\hline ME & $11 \pm 0.40^{\mathrm{a}}$ & 0.14 \\
\hline EE & $12 \pm 0.00^{\mathrm{a}}$ & \\
\hline Note: ${ }^{\mathrm{a}}$ Total number of days required for complete wound healing is significantly \\
\hline \multicolumn{2}{|c|}{ shorter than negative control $(\mathrm{p}<0.001)}$. \\
\hline
\end{tabular}




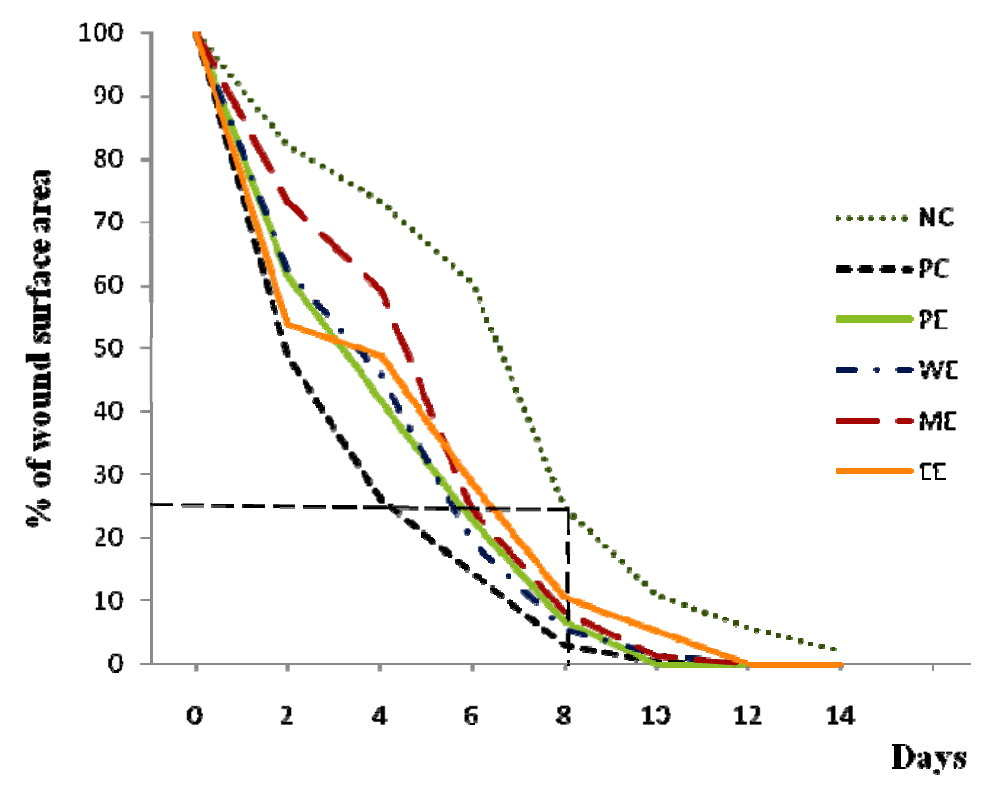

Figure 1. Percentage wound reduction at different time intervals in the treated and the untreated wounds $\mathrm{NC}=$ Control (no treatment), $\mathrm{PC}=$ Solcoseryl, $\mathrm{PE}=\mathrm{PBS}$ seed extract, $\mathrm{WE}=$ Water seed extract, $\mathrm{ME}=$ Methanol seed extract, $\mathrm{EE}=$ Ethanol seed extract. 